Rhode Island College

Digital Commons @ RIC

$1-1-2012$

\title{
Effects of a Simulation Educational Experience on Critical Care Staff's Recognition of Stressors Affecting Performance and Use of Teamwork Skills
}

Heidi K. Paradis

Rhode Island College

Follow this and additional works at: https://digitalcommons.ric.edu/etd

Part of the Geriatric Nursing Commons

\section{Recommended Citation}

Paradis, Heidi K., "Effects of a Simulation Educational Experience on Critical Care Staff's Recognition of Stressors Affecting Performance and Use of Teamwork Skills" (2012). Master's Theses, Dissertations, Graduate Research and Major Papers Overview. 200.

https://digitalcommons.ric.edu/etd/200

This Major Paper is brought to you for free and open access by the Master's Theses, Dissertations, Graduate Research and Major Papers at Digital Commons @ RIC. It has been accepted for inclusion in Master's Theses, Dissertations, Graduate Research and Major Papers Overview by an authorized administrator of Digital Commons @ RIC. For more information, please contact digitalcommons@ric.edu. 
EFFECTS OF A SIMULATION EDUCATIONAL EXPERIENCE ON CRITICAL CARE STAFF'S RECOGNITION OF STRESSORS AFFECTING PERFORMANCE AND USE OF TEAMWORK SKILLS

A Major Paper Presented

by

Heidi K. Paradis

Approved:

Committee Chairperson

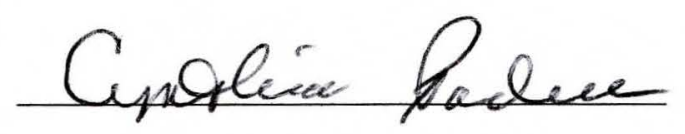

$\frac{5 / 10 / 12}{(\text { Date })}$

Committee Members
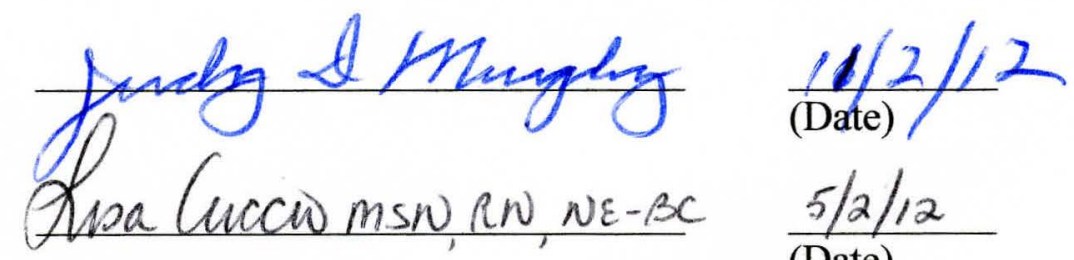

Director, Master's Program

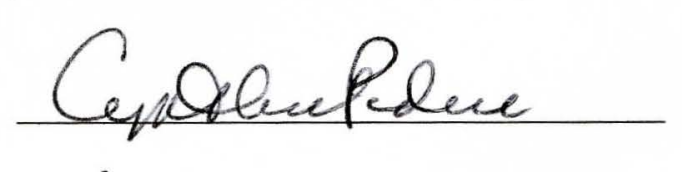

$\frac{5 / 2 / 12}{\text { (Date) }}$

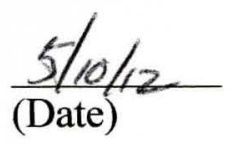

Dean, School of Nursing
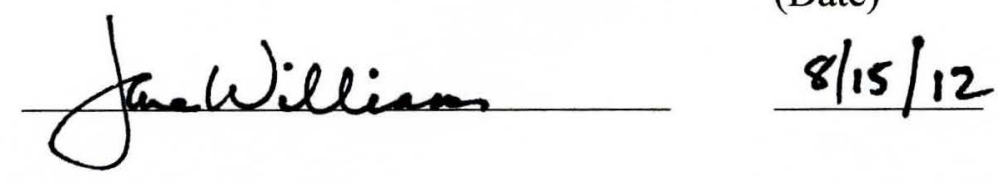


\section{EFFECTS OF A SIMULATION EDUCATIONAL EXPERIENCE ON CRITICAL CARE STAFF'S RECOGNITION OF STRESSORS AFFECTING PERFORMANCE AND USE OF TEAMWORK SKILLS}

\section{Heidi K. Paradis}

A Major Paper Submitted in Partial Fulfillment

Of the Requirements for the Degree of

Master of Science in Nursing

in

The School of Nursing

Rhode Island College

2012 


\begin{abstract}
Background: Human limitations are sources of medical error that result in injuries, deaths and cost reaching millions. Preventing human errors from reaching patients is an imperative goal of a healthcare system that desires to reduce costs and produce quality outcomes. There is a mounting body of evidence that safety culture measurement and intervention can impact the safety and quality of healthcare.
\end{abstract}

Objective: To impact the safety culture attitudes of critical care professionals by providing a teamwork training that incorporated simulation.

Methods: The purpose of this study was to examine the effect of teamwork training on critical care staffs' safety culture and teamwork attitudes. A pre and post quasiexperimental design was employed. The sample included critical care professionals working in four critical care areas. The intervention was an 8 hour training involving teamwork didactic and simulation experiences. Data were collected via attitude surveys immediately before and after the training and two months following training.

Results: The difference in median values between individuals' pre and post attitude scores was significant $(\mathrm{p}<.001)$. Aggregate data showed three of the four critical care units and critical care as a whole, significantly improved key safety culture mean scores yet scores remained critically low.

Conclusions: The teamwork training with simulation was effective at impacting individuals' safety culture attitudes. The training had a positive impact on unit level safety culture; however, not enough for it to be considered a healthy climate, indicating the need for continued, broader intervention. 


\section{Acknowledgements}

I would like to acknowledge several individuals at Rhode Island College School of Nursing for the invaluable support in accomplishing this project. Without their support this project would not have been possible and certainly not as successful. I would like to specifically thank Dean Jane Williams who granted the use of the nursing simulation laboratory at RIC. Judy Murphy, the simulation coordinator, was a vital expert resource in creating and executing the simulation experiences. Fatima Morel-Silva, the nursing lab coordinator, enthusiastically helped to make the experiences both realistic and enjoyable. Lois Ginsberg, RIC faculty, and TMH colleague, assisted me with planning, implementing and evaluating the educational intervention. She also encouraged me to disseminate the results by presenting the project at both a regional critical care conference and a national professional development conference. I am most grateful for the extraordinary mentorship, guidance, and constant support from Cynthia Padula, graduate nursing program director. She is an exemplary advanced practice nurse, researcher, educator and mentor.

Most of all I would like to acknowledge my family, and most specifically my loving husband Bill, who unselfishly provided immeasurable support and encouragement in my endeavor to pursue my educational and career goals. They truly are the "wind beneath my wings". 
Table of Contents

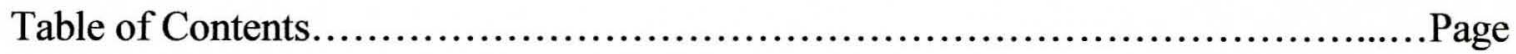

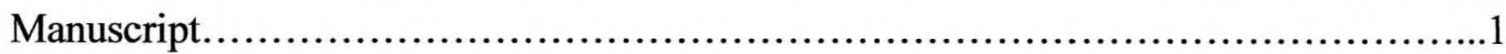

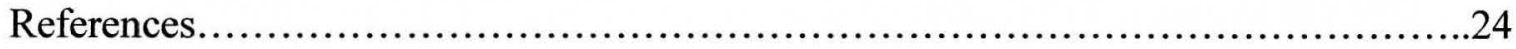

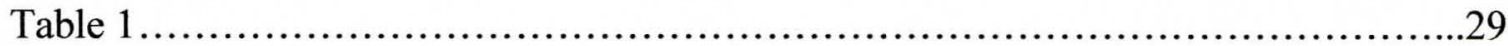

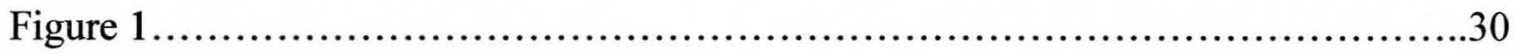

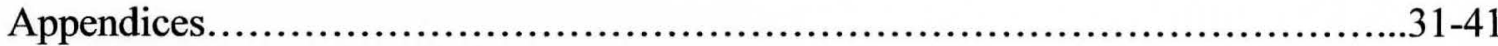


The Effect of a Simulation Educational Experience on Critical Care Staff's Recognition of Stressors Affecting Performance and Use of Teamwork Skills

\section{Background}

Patients today have no guarantee of high quality care that is free from risk or harm. Although most patients receive treatment that improves their health and/or quality of life, an unacceptable number are harmed as a result of their encounter with the health care system (Carthey \& Clark, 2009). Although it is the responsibility of all who work in healthcare to ensure safe, quality care, nurses are in an extraordinarily influential position to impact the safety and quality of care.

The patient safety movement was highly influenced by the release of the Institute of Medicine (IOM) report To Err is Human: Building a Safer Health System (Kohn, Corrigan, \& Donaldson, 2000), which called for the health care industry to open its eyes and mouths on the subject of patient error. This report provided staggering figures on the number of deaths due to medical errors annually (44 to 98,000) and the associated cost, “estimated between $\$ 17$ billion and $\$ 29$ billion, of which health care costs represent over one-half" (p. 1). The harm caused to patients results in emotional stress for those who caused it and in a loss of faith in the system by the consumers who depend on it. The report urged the health care profession to build an organizational culture that encourages recognition of and learning from errors. A paradigm shift that challenged the health professions to recognize that human beings make errors and that it is crucial to learn from them and revise our systems to compensate for human limitations was urgently needed. 
Subsequently, many organizations, such as the Agency for Healthcare Research and Quality (AHRQ), National Quality Forum (NQF), and The Joint Commission (TJC), sharpened their focus on patient safety as a requirement for quality. Many new organizations formed and legislation was passed to help ensure the safety of patients and to promote research to discover and share best practices to prevent error. There has also been a steady growth of research related to errors in health care, which include communication, physical environment, assessment, leadership, and human factors (TJC, 2011). James Reason (2000) focused on human factors or limitations that make us prone to errors, and proposed that it is rarely one factor that causes a sentinel event. It is usually a series of smaller, minor mistakes, when lined up together that lead to a larger event. A systems approach means recognizing these threats and embedding systems with barriers and defenses that mitigate for inevitable human error (Reason, 2000). A culture of safety is one in which all members of the healthcare team are aware of and on the lookout for these threats, and also one where best practices are used by all to prevent failures. Adding to the evidence supporting the importance of safety culture, TJC now requires hospital leadership to create and maintain a culture of safety. Leaders are expected to evaluate the safety culture using valid, reliable tools and then implement changes accordingly (TJC Accreditation Manual E-edition, 2010). Nurses, particularly in advanced practice roles, are uniquely positioned to help build a culture of safety and to incorporate research to promote practice and system changes that compensate for human limitations that lead to error. Safety culture assessment should be used to discover areas 
of improvement that could lead to fewer adverse events, improved outcomes, and potentially decreased costs.

\section{Definition of the Problem}

At the Miriam Hospital (TMH), a 247 bed community hospital within the Lifespan Network, leadership continuously strives to maintain the safety culture through on-going assessment and planning for improvement. One validated assessment of multiple domains of the safety culture is the Safety Attitude Questionnaire (SAQ) (Sexton et al., 2006), which has six subscales: teamwork climate; safety climate; job satisfaction; stress recognition; working conditions; perceptions of hospital management; and perceptions of unit management. As part of a state-wide ICU Collaborative, TMH critical care units annually used the SAQ to evaluate the safety culture, and all units made significant improvements (greater than 10 percentage points) over the past four years in five of the six domains. In 2010, TMH participants scored among the highest in the state overall in the safety climate and working conditions domains. However, during the same time period, TMH respondents remained among the lowest (below the 'danger zone' of 60\%) in the stress recognition subscale. This category measures the acknowledgement of how performance is influenced by stressors, an important skill in order to successfully discuss and learn from errors. In other words, staff respondents did not recognize, and may continually deny, the effect of stress and fatigue on their performance. In a healthy safety culture, recognition of these human limitations reduces the likelihood of error by increasing the use of threat and error management strategies (Sexton, Thomas \& Helmreich, 2000). 
This author, the critical care educator at TMH, questioned what could be done to improve staffs' awareness of their human limitations, explore strategies that might compensate for these factors, and also make them aware of how not doing so leads to error. A literature review was conducted to identify an evidence based approach that might involve simulation as a strategy. As a result, the author developed a simulation based educational intervention to potentially improve the SAQ scores. The purpose of this study was to evaluate the effect of such an educational experience on the staffs' ability to recognize how stressors affect their performance and lead to error and to learn strategies to counteract this human limitation.

\section{Literature Review}

\section{Impact/Etiology of Errors}

The staggering financial and emotional cost of error was poignantly outlined in the 2001 IOM report that estimated that 1.3 million patients are injured each year due to medical error. One major recommendation was that the healthcare system needed to be redesigned in terms of processes and systems to compensate for the limits of human behavior. The patient safety movement began with an attempt to learn from errors by reporting and analyzing them.

Root cause analysis is a structured method for analyzing serious adverse events in order to learn what factors contributed to the event so that they can be eliminated or minimized by system redesign. Since 2004, TJC has kept and reported root cause analysis data, which has demonstrated that human factors are consistently among the leading causes of errors (TJC, 2011). Many articles cite the seminal works by Rasmussen 
(1990) and Reason (1990), who described the performance of humans and those factors that impact limitations of human physical and cognitive performance. Human factors include fatigue, multitasking, distraction, illness, stress, workload, lack of knowledge and training, and inadequate communication, which have a negative impact on performance and make error more likely. When combined with "holes" or inconsistencies in systems and processes, these factors make the perfect storm for error. Such factors include the effect of stress and fatigue, both of which impair performance (Sexton, et al., 2000). These authors studied teams that worked in safety-critical environments and collected data on attitudes that could be used to design training, including simulation, as a systems approach to improve teamwork as an error prevention strategy. One of the authors, Robert Helmreich, had done extensive work in the aviation field, and found that attitudes toward stress, teamwork, and error are linked to performance and are susceptible to training. In their 2000 study, the authors surveyed 1033 medical personnel from the Intensive care and Operating Room areas as well as 30,000 airline cockpit crew members over three years to compare their attitudes toward error, stress and teamwork. The respondents included cockpit crew members from 40 different airlines in 25 countries over 15 years and medical staff from 12 urban hospitals in several countries. Surveys contained 23 core elements worded specifically for each environment and that measured attitudes toward stress, status hierarchies, leadership, and interpersonal interaction issues. Sixty to $70 \%$ of medical staff believed they performed effectively when fatigued or during critical events, as compared to $26 \%$ of aviation staff. Seventy percent of medical personnel agreed with statements that denied the effect of stress and fatigue on 
performance. The authors concluded that this difference may be due to more extensive simulation and teamwork safety training, or crew resource management, in aviation.

In 2005, Rothschild and others conducted a prospective one year observational study to examine the incidence and nature of adverse events and serious errors in the critical care setting. A total of 120 adverse events occurred, of which 54 were preventable. There were also 223 serious errors identified, the most serious occurring during the ordering or execution of treatments. They also noted performance level failures were more often "slips and lapses rather than rule-based or knowledge-based mistakes" (p. 1697).

In a qualitative study, Wetzel et al. (2006) conducted 16 interviews with a purposive sample of London surgeons in order to explore surgical stressors, their impact on performance, and coping strategies used. Semi-structured interviews of individual surgeons were conducted. Findings identified that undue levels of stress impaired judgment, decision-making, and communication. Senior surgeons, in contrast to junior surgerons, were found to have developed strategies for controlling stressful situations, suggesting that such strategies could be learned.

West, Tan, Habermann, Sloan, and Shanafelt (2009) conducted a prospective longitudinal cohort study of 380 medical residents to determine the association of fatigue and distress with self-perceived major medical errors. The researchers used electronic surveys that included self-assessment of medical errors, and validated survey tools to measure fatigue, quality of life (QOL), burnout, and symptoms of depression. Errors were reported by 139 (39\%) participants. Reports of error were associated with the Epworth Sleepiness Scale score $(\mathrm{p}=.002)$ and fatigue score $(\mathrm{p}<.001)$. Subsequent error 
was also associated with burnout $(\mathrm{p}<.001)$ emotional exhaustion $(\mathrm{p}<.001)$; lower personal accomplishment $(\mathrm{p}<.001)$, a positive depression screen $(\mathrm{p}<.001)$, and overall quality of life $(\mathrm{QOL})(\mathrm{p}<.001)$. The authors concluded that higher levels of fatigue and distress among medicine residents were independently associated with self-perceived medical errors.

Nurses are not immune from the effects of fatigue. Rogers et al. (2004) conducted a study using logbooks completed by a nation-wide random sample of 393 staff nurses who were also ANA members. The purpose of this study was to determine if an association existed between occurrence of error and hours worked by nurses. Participants recorded information about hours worked and answered questions about errors and near errors they may have made. Nurses who worked more than 12.5 hours were three times more likely to make an error (odds ratio [OR] 3.29; $\mathrm{p}=.001$ ) and those working more than 40 hours per week significantly increased the risk of making an error (OR 1.96; $\mathrm{p}<.0001)$. Scott, Rogers, Hwang and Zhang (2010) repeated this study with a random sample of 502 American Association of Critical Care Nurses (AACN) members. They also concluded that the risk of error nearly doubled for nurses working more than 12 hours (OR 1.94; $\mathrm{p}=.03$ ), and noted that these findings support the IOM recommendations to minimize the use of 12 hour shifts and to limit shifts to no more than 12 hours.

An experimental within-subjects comparison study evaluated the impact of prolonged continuous wakefulness on resident performance during the management of a simulated patient deterioration (Sharpe et al., 2010). Performance was studied during 26 hours of wakefulness at four time points. The frequency of errors was assessed by scorers blinded 
to the time interval, and overall performance was scored using a rating scale. An increase in the mean number of errors $(\mathrm{p}=.09)$ and a decrease in performance $(\mathrm{p}=.02)$ as hours of wakefulness increased over time was detected, and the authors concluded that fatigue adversely affected performance and led to errors. Landrigan (2010) noted that Sharpe's study adds to the "compelling body of evidence" (p.980), including more than 80 relevant studies, that led to the IOM call for the elimination of shifts exceeding 16 hours without sleep. Long shifts, however, continue to remain the norm at many hospitals. This fact, combined with the knowledge that health care workers deny the effects of stress and fatigue on performance, should cause concern amongst nurse leaders. Allowing controllable human factors such as these to be culturally accepted in the nursing profession leaves us vulnerable to error (Denham et al, 2007).

\section{Safety Culture Interventions}

In compliance with TJC recommendations, most hospitals assess safety culture to discover staffs' attitudes that might increase the risk of error, which then provides the opportunity to develop and implement action plans. The Safety Attitude Questionnaire (SAQ) (Sexton et al, 2006) provides specific information about staffs' recognition of the relationship between human factors such as stress and fatigue and performance. With information from this measurement tool, safety and quality improvement initiatives can be designed and implemented at the unit level to achieve sustainable results (Hudson, Berenholtz, Thomas, \& Sexton, 2009).

Pronovost et al. (2008) studied the impact of a Comprehensive Unit based Safety Program (CUSP) of evidence based practices on the team climate scale of the SAQ in 72 
intensive care units across Michigan. A total of 4,474 surveys ( $75 \%$ response) completed in 2004 were compared to 3,876 surveys (65\% response) collected in 2005 . One year post intervention, team climate scores on the SAQ improved significantly $(p<.005)$, and adherence to some evidenced based measures improved. This study provides support that a unit-level improvement project involving education can impact the safety culture. Improvements in safety culture have been associated with positive patient outcomes. In a cohort study, Huang et al. (2010) combined safety culture survey data with the Project IMPACT Critical Care Medicine (PICCM) clinical database. The purpose of the study was to determine if ICU safety culture was independently associated with patient outcomes. A total of 2,103 SAQ surveys returned from 4,373 ICU personnel (47.9\% response) comprised the culture survey data. A sample of 65,978 patients admitted to 30 participating multicenter ICUs from 2001-2005 was also included; outcomes examined included mortality and length of stay (LOS). For every $10 \%$ decrease in perceptions of management score, the increased odds of death were $1.24(p<0.0001)$. Lower safety climate was significantly associated $(\mathrm{p}<0.03)$ with increased LOS. For every $10 \%$ decrease in score, LOS increased $15 \%(\mathrm{p}=0.03)$. This study adds evidence that interventions to improve safety culture may positively affect patient outcomes in the intensive care setting.

\section{Simulation as Safety Culture Intervention}

The IOM (2000) and AHRQ (2001) identified simulation as a best practice tool to engage and educate practitioners in health care in order to prevent and mitigate harm. Other organizations, including the American College of Surgeons, the American Council 
for Graduate Medical Education and the National League for Nursing and AACN, also support the use of simulation to enhance learning (Cato \& Murray, 2010).

A systematic review conducted by Cant and Cooper (2009) provided an extensive evaluation of the evidence behind simulation as an educational tool in nursing. The review included 12 quantitative studies that compared the effectiveness of medium and high fidelity simulations compared to other methods of education such as lecture, group interaction, case studies, debriefings, or tests. Only one study was a randomized controlled trial; most were pre and post-test quasi-experimental studies with a comparison group. Seven studies included a validated assessment measure. All 12 studies showed statistical improvements in knowledge, skill, critical thinking ability, and/or confidence after simulation education (p. 6), and over half showed simulation to be superior to other methods. What is lacking in the evidence is a standardized tool for measurement of the effect of simulation.

Many studies using simulation and team training were found in the emergency, labor and delivery, and OR arenas. Morey et al. (2002) conducted a prospective investigation using a quasi-experimental, untreated control group design. The Emergency Team Coordination Course ${ }^{\mathrm{TM}}$ (ETCC) served as the intervention and included elements of crew resource management. The experimental group $(n=684$ varied practitioners $)$ participated in the ETCC and implemented formal teamwork structures and processes. Assessments occurred prior to training, and at four and eight months after. Trained observers rated ED staff team behaviors and made observations of clinical errors as a measure of ED performance. Staff and patients in the EDs completed surveys measuring attitudes and 
opinions. Statistically significant $(\mathrm{p}=.012)$ improvements in the quality of team behaviors and reduction in clinical errors $(\mathrm{p}=0.39)$ were among the results. ED staffs' attitudes toward teamwork increased ( $p=.047)$ and staffs' view of institutional support increased $(p=.040)$.

Shapiro et al. (2004) tested an intervention involving a didactic training in ETCC, combined with simulation. The researchers used a single, crossover, prospective, blinded and controlled observational design. Outside-trained observers in the ED completed teamwork ratings using validated behaviorally anchored rating scales (BARS). Four ED teams were randomly assigned to two control groups (didactic training) and were compared with two experimental groups (simulation added). The experimental team showed an improvement in the quality of team behavior $(p=0.07)$, while the comparison group did not.

Miller, Riley, Davis and Hansen (2008) conducted a pilot study of 35 simulated obstetric emergencies involving 700 participants. The researchers designed the simulations to replicate stressful events that participants might encounter. Teamwork competencies based on the TeamSTEPPS ${ }^{\circledR}$ Curriculum (AHRQ and DoD, 2004) were evaluated. Participants evaluated their own performance and discussed failures and errors that occurred. Debriefing was emphasized, and debriefing and education occurred in a spacious conference room with food and drinks to enhance participants' comfort. Participants identified areas where they did not perform well and also participated in problem solving to find ways to improve their performance and identify systems issues that could be improved. The researchers analyzed videotapes, provided findings to unit 
level leaders, and then developed process improvement initiatives and further team training. The authors compared SAQ scores two months before and six months after the 12 simulation trainings. Although the hospital aggregate data showed no improvement, the perinatal unit had significant improvement in six indices, including improvement at the unit level in teamwork (increased by 5.9\%). Follow-up from participants was viewed as crucial because cognitive changes may occur several days after the simulation.

It is clear that safety culture is related to both error and patient outcomes. The safety culture can be measured and is amenable to intervention for improvement. Teamwork and simulation training as a combined intervention were supported as evidence based strategies that can be used to impact ICU staff attitudes, critical to the safety culture.

\section{Theoretical Frameworks}

Lazarus' theory of Stress Appraisal and Coping and Kolb's Experiential Learning Theory (1984) were used to guide development of the study intervention. Lazarus and Folkman (1984) defined stress as "a particular relationship between the person and the environment that is appraised by the person as taxing or endangering his or her wellbeing" (p21). Humans respond differently to the same stressors and each person evaluates the significance of a situation and reacts accordingly, described as cognitive appraisal. Three types exist: in primary appraisal, a person judges an encounter as irrelevant, benign, or stressful; during secondary appraisal, one considers what can be done; in re-appraisal, the individual changes his/her view of the experience based on new information (Lazarus \& Folkman, 1984). Person factors influence cognitive appraisal, including commitments and beliefs, especially beliefs about personal control. Appraising 
an outcome as controllable is stress reducing. When commitment is deep, motivation for ameliorative action is increased. Situation factors that influence cognitive appraisal include novelty, predictability, and uncertainty. New and unpredictable situations can cause increased stress; therefore practicing and preparing for events until they are familiar can reduce the stress response (Lazarus \& Folkman, 1984). Providing strategies or resources can influence the secondary appraisal and affect a person's response to stress. Resources include health and energy (including positive beliefs), problem solving skills, social skills, and material resources. There are also constraints that influence a person's coping, including internalized cultural beliefs and values (Lazarus \& Folkman). An intervention designed to stimulate individuals to appraise situations differently and provide resources to cope effectively may assist in managing stress.

David Kolb's Experiential Learning Theory was also considered in designing the intervention. Kolb's theory posits that learners construct new knowledge by adding what is learned from new experiences to what is already known (Billings \& Hallstead, 2009). Kolb suggested (1984) that learning occurs in a continuous cyclical pattern. Learners interact in a real experience, then reflect on that experience, create meaning, and fit that into existing knowledge. That meaning is then applied to new experiences by thinking and acting differently. Learning is a process where ideas and concepts are formed and reformed through application in experience. This theory can readily be applied to simulation as an educational tool in clinical practice (Billings \& Hallstead, 2009). Simulation followed by didactic learning provides for immediate application of learning to a simulated realistic experience, and debriefing allows participants to reflect on their 
performance to create change for improvement in attitude and behavior. Improvements in performance with use of teamwork skills during patient care events should translate into fewer errors and better patient outcomes.

\section{Methods}

\section{Purpose}

The purpose of this study was to determine the effect of an eight hour teamwork training with didactic and simulation on critical care staffs' individual and unit level safety culture attitudes.

\section{Design}

A before and after quasi-experimental design was used for the study. The independent variable was the simulation intervention; the dependent variables were individual and unit level safety culture attitudes.

\section{Site and Sample}

The site was Rhode Island College (RIC) nursing simulation laboratory. The College generously allowed the use of the lab and the simulation faculty contributed their time. The potential sample consisted of multidisciplinary health professionals, including registered nurses, physicians (attending and fellows), physician assistants, and respiratory therapists employed at TMH. Inclusion criteria included all of these critical care professionals who provided direct patient care; there were no exclusion criteria.

\section{Procedures}

The proposal was approved by both the Lifespan and Rhode Island College Institutional Review Boards (IRB). Following IRB approval, participants were recruited 
from all four critical care units. The researcher posted and emailed an IRB approved flyer (Appendix A) to eligible staff. The project purpose and overview was also announced at staff meetings. It was emphasized that critical care staff who agreed to participate would be required to attend one eight-hour simulation educational training day at the RIC Simulation lab between January and March 2011. Interested participants contacted the researcher directly, at which time an informational letter (Appendix B) was provided and participants identified a date to attend the intervention.

\section{Measurement}

Three distinct measurement instruments were used: the Safety Attitude Survey (SAS) (Appendix C); the Teamwork Attitudes Questionnaire (TAQ) (Baker, Krokos and Amodeo, 2008) (Appendix D); and the Safety Attitude Questionnaire (SAQ) (Appendix E). The SAS was used to measure acknowledgment of how performance is influenced by stressors. After discussion and advisement from the originator of the SAQ, J.B. Sexton (personal communication, March/April 2009), 11 items comprising the stress recognition subscale of the SAQ ICU version were used and three items related to knowledge and use of error prevention strategies were added for purposes of this project. Responses use a Likert scale with scores ranging from 1-5 $(1=$ strongly agree; $5=$ strongly disagree $)$. The TAQ was developed by the U.S. Department of Defense to be used with the TeamSTEPPS ${ }^{\circ}$ program. Baker, Krokos, and Amodeo (2008) developed and pilot tested the tool. The 30 item TAQ measures six constructs: team structure; leadership; mutual support; situation monitoring; and communication. Responses on a Likert scale range from strongly agree to strongly disagree $(1=$ strongly agree; $5=$ strongly disagree $)$. 
Cronbach alphas range from .70 to .83 . The SAQ was developed and refined from the medical translation of a questionnaire used extensively in the aviation industry (Sexton et al., 2000). Many organizations use this survey to measure their safety culture and benchmarking data is available (Sexton et al, 2006). The short form of the University of Texas SAQ was used to measure unit level safety culture attitudes since this is the version used historically at our institution. The authors reported reliability using Raykov's $p$ coefficient of 90 . Four items comprise the stress recognition scale in this version of the tool. The scores in this category were the target of interest for comparison.

\section{Intervention}

The intervention included an eight hour educational training incorporating didactics and simulation (Appendix F). On the day of training, the informational letter was reviewed and any questions answered. Participants completed the SAS (Appendix C) and the TAQ (Appendix D) pre-intervention. Participants then attended an eight-hour educational session, the TeamSTEPPS $®$ Curriculum (AHRQ \& DoD, 2004). This is an evidence-based training developed by the Department of Defense (DoD) and the AHRQ to optimize team performance to mitigate for the human limitations of individuals. The training includes four core competency areas: leadership; situation monitoring; mutual support; and communication, which contribute to improved team performance, safer practices, and change in culture. This interactive session included identifying sources of stress and fatigue, their effects on performance, techniques to mitigate these stressors, and other team based error management strategies. The curriculum used interactive group activities and video clips to illustrate concepts and role play to apply concepts and 
strategies. After the didactic portion, participants received a brief orientation to the simulation center environment. Next, participants actively participated in a 10-15 minute simulation scenario using high fidelity equipment. The researcher, with the assistance of simulation center personnel, developed the simulation scenarios to replicate patients whose condition deteriorated. A confederate role player intentionally set up a medication error. Participants responded as a team to the situation as they normally would, but were asked to try to implement some of the concepts they learned about during the training. Videotaping was used to guide debriefing and enhance learning but participants were assured that it was not being used for evaluative purposes and would not be stored but erased immediately after debriefing. During a 20-30 minute debriefing, the participants were guided to discuss the scenario and whether they were able to implement any of the concepts learned. Any adverse events were discussed and contributing factors explored. Participants had another opportunity to apply concepts to a second simulated experience, and were encouraged to discuss how they could apply teamwork techniques to improve performance in order to prevent errors. In a second debriefing, participants again viewed their performance, discussed how stressors affected their performance, how they used strategies to prevent error, and how these strategies could be applied to future practice. At the conclusion of the program, participants again completed the SAS and the TAQ as well as a course evaluation. Pre and post surveys were linked with a de-identifiable code. A total of six sessions were offered.

All staff on the four critical care units (not just those who attended the training) then received an electronic link via email to complete the SAQ in May, two months after 
training was completed, with a 50\% response rate This optional, confidential, and anonymous survey was administered via survey monkey. SAQ scores completed October 2010 (response rate $75 \%$ ) as part of the statewide ICU collaborative were compared to scores completed post intervention to measure effect of the training on the unit-level safety culture, specifically the stress recognition category.

\section{Data Analysis}

Data were analyzed using Sigma Stat. Descriptive statistics were performed on all data.

\section{Results}

Twenty seven participants completed both the program and the pre and post surveys, with no missing data. All items on both the TAQ and the SAS showed a difference between pre and post scores that indicated greater agreement with the items. A MannWhitney rank sum test showed that the difference in median values between the pre and post scores were significant for the TAQ $(p<.001)$ and for the SAS $(p<.001)$. Greater difference overall was seen in the SAS before and after scores, those indicating recognition of how stressors impact performance, than the TAQ before and after scores, those indicating agreement with teamwork concepts (Table 1). The differences in before and after mean scores of the stress recognition items (SAS) ranged from .111 to .926 (overall difference .545). The Teamwork concepts mean score differences ranged for Team Structure .148 to .593 (overall difference .371), Leadership .074 to .259 (overall difference .197), Situation Monitoring .260-.408 (overall mean difference .320), Mutual Support .185-.333 (overall difference .259) and Communication .37-.85 (overall 
difference .545). The largest difference in concept means was seen in the communication subscale of the TAQ which includes items that acknowledge that poor communication among teams can lead to error and effective communication strategies can help prevent error.

Aggregate SAQ scores from November 2010 (pre-intervention) were compared to aggregrate SAQ scores completed post intervention. For purposes of this research, only scores on the stress recognition subscale, which is comprised of four items, will be reported. Scale scores (mean of all four items in this scale) were calculated for each of the four critical care units and compared to previous scores. A mean scale score for critical care as a whole was also calculated. According to Pascal Metrics Inc., a clinical risk management consulting team that administered the survey for the ICU collaborative, an improvement of $10 \%$ or more is considered meaningful and likely to be statistically and practically significant, while smaller differences are more likely due to random variation. Scores are reported as percent positive or the percent of those answering agree or strongly agree with a given item or scale. The goal is to reach $80 \%$ positive, indicating that four out of five agree that the climate is good. Scores below $60 \%$ ("danger zone") are considered in need of improvement.

As illustrated in Figure 1, three of the four critical care units improved their stress recognition scale scores by $10 \%$ or more (ICU $10 \%$, CVTS $26 \%$, CVTI $11 \%$ ) while one unit decreased by $1 \%(\mathrm{CCU})$. The mean stress recognition scale score for critical care as a whole overall improved significantly from 36 to $47.5 \%$. All scale scores remained under $60 \%$. Three of the four individual items making up the scale showed small 
improvements (less than 10\%). For the item: "Fatigue impairs my performance during emergency situations," the mean scores for critical care showed significant improvement (from 35 to $63 \%$ ), and three of the four units showed significant improvement ( $30 \%$, $27 \%, \& 14 \%$ ) on this item. This one item lifted slightly above the $60 \%$ danger zone.

\section{Summary and Conclusions}

The inability of interdisciplinary critical care staff to recognize that stress and fatigue alter their performance is a serious risk factor that requires ongoing, intensive intervention. Teamwork training, guided by experiential learning theory, and combined with evidence based strategies and simulation experience contributed to a synergistic learning experience. Participants' evaluations of the program (Appendix G) indicated that all agreed that course objectives were met; participants were satisfied with the training, and most added comments that this training should be mandatory for all employees. Many commented on how valuable the debriefing aspect was to apply learning to practice.

The significant differences in pre and post survey scores demonstrated that the teamwork training with simulation was effective at impacting individuals' safety culture attitudes. This change in attitude was evident during the video debriefings. Also during the debriefing, the embedded medication error was revealed. Only one group caught the error during simulation. The other groups had to be shown the error they had made and were very surprised. This stimulated much discussion about how strategies could be used to prevent such errors. Other lapses in performance were noted by participants and again generated discussion on how the strategies learned could be used to improve 
performance. Team strategies were more frequently used in the second scenario following this discussion. Staff acknowledged the important link between communication and error and the negative impact that stressors have on performance that can lead to error. Participants recognized that working and communicating as a team is a strategy that can help to mitigate for this risk and improve patient safety.

At the broader culture level, some significant improvement in scores was seen, possibly indicating that the training did have some impact on safety culture. However, the culture scores as a whole were still below what is desirable and remained in the danger zone, indicating the need for continued and broader intervention.

Limitations included the limited number of participants; since only $20 \%$ of critical care professionals participated, short and long term impact on the culture as a whole is expected to be limited. Likewise, the intervention was included in one limited time period; repeating the intervention, and also exploring alternative strategies, including intermittent 'booster' classes, is indicated. It is possible that other ongoing patient safety initiatives such as a communication improvement initiative in the ICU may have had some influence on participants' attitudes. Continued monitoring with the SAQ, administered two months after training, would be beneficial.

Results were shared with the Department of Nursing and hospital leadership, and funding for continued training has been provided. Continued refinement and on-going support of this training will ideally result in practitioners who can recognize and manage the effects of stress and fatigue on performance during clinical events. Improved individual and team performance could logically translate into reduced error, thus 
potentially creating a safer environment. The institution has endeavored to create a safety culture where risks are reported and error is reduced. When errors do occur as a result of human limitations, there is tremendous ability to learn from those mistakes. This project has certainly contributed to that goal.

\section{Implications for Practice}

Consistent with the literature (Cant \& Cooper, 2009), the video debriefing, where participants viewed and analyzed their performance and then discussed how the concepts learned could be implemented in practice, seemed to be the most crucial learning aspect. During debriefing, participants were able to recognize factors that influenced their performance and discuss specific strategies that could be used to compensate for impaired performance. Simulation is a highly effective tool for nurse educators to use to illustrate clinical issues that cannot readily be taught in practice.

The significant, positive effect of this training on individual attitudes should interest nursing leaders who are responsible and accountable for the safety culture in their practice environments. The improvement in the recognition that fatigue impairs performance is also an important finding in light of the Patient Safety Advisory Group's recent 2011 Joint Commission Sentinel Event Alert on health care worker fatigue and patient safety. The alert calls attention to the impact of fatigue, contributing factors to fatigue, and risks to patients. Actions suggested as part of safety culture include encouraging "teamwork as a strategy to support staff who work extended work shifts or hours and to protect patients from potential harm" (p. 2). 
The cost of simulation and the skill required to develop and fully implement simulation scenarios are potential barriers to simulation intervention and research. Despite these constraints, simulation provides such a rich, valuable experience that the investment is worthwhile. Hospitals would be wise to invest in simulation equipment and training for educators so that this innovative, evidence-based strategy can be used as an effective means to impact employee's performance. Improvements in safety culture have been associated with sustained improvements in medication errors, length of stay, nursing turnover rates, and bloodstream infection rates (Hudson et al, 2009). Future studies might continue to explore and expand the impact of various types of improvements in safety culture on patient outcomes such as these. A critical question that remains is whether simulation training that results in improvements in safety culture translates to improved and sustained patient outcomes. 


\section{References}

Agency for Healthcare Research and Quality. (2001, July 20). Making health care safer: A critical analysis of patient safety practices (Archived EPC Evidence Reports AHRQ Publication 01E058). Retrieved from AHRQ website: http://archive.ahrq.gov/clinic/ptsafety/

Agency for Healthcare Research and Quality (AHRQ) and the US Department of Defense (DoD). (2004). TeamSTEPPS® Curriculum. Rockville, MD:US Agency for Healthcare Research and Quality.

Baker, D., Krokos, K. \& Amodeo, A. (2008). TeamSTEPPSTM teamwork attitudes questionnaire manual (Prepared for US Department of Defense, Tricare Management Activity). Washington, DC: American Institutes for Research. Billings, D. \& Halstead, J. (2009). Teaching in Nursing (3rd ed.). St, Luis Missouri: Saunders Elsevier.

Cant, R. P. \& Cooper, S. J. (2009). Simulation-based learning in nurse education: Systematic review. Journal of Advanced Nursing, 66(1), 3-15.

Carthey J. \& Clark J. (2009). The 'how to guide' for implementing human factors in healthcare.

London: Patient Safety First. Retrieved from clinical human factors group website: http://www.chfg.org

Cato, D. \& Murray, M. (2010). The use of simulation training in the intensive care unit. Critical Care Nursing Quarterly, 33(1), 44-51. 
Denham, C., Dingman, J., Foley, M., Ford, D., Martins, B., O’Reagan, P. \& Salamendra, A. (2008). Are you listening...Are you really listening? Journal of Patient Safety, $4(3), 148-161$.

Huang, D., Clermont, G., Kong, L., Weissfeld, L., Sexton, J.B., Rowan, K., and Angus, D. (2010). Intensive care unit safety culture and outcomes: A US multicenter study. International Journal for Quality in Health Care, 22(3), 151-161.

Hudson, D., Berenholtz, S., Thomas, E., Sexton, J.B. (2009). A Safety culture primer for the critical care clinician: The role of culture in patient safety and quality improvement. Contemporary Critical Care, October, 7(5), 1-12.

Kohn, L., Corrigan, J. \& Donaldson, M. (Eds.). (2000). To err is human: Building a safer health system. Washington, DC: National Academy Press.

Kolb, D. (1984). Experiential learning: experience as the source of learning and development. Englewood Cliff, NJ: Prentice Hall.

Landrigan, C. (2010). Resident sleep deprivation and critical care: The unintended consequences of inaction. Critical Care Medicine, 38(3), 980-1.

Lazarus, R.S. \& Folkman, S. (1984). Stress, Appraisal and Coping. New York: Springer

Miller, K., Riley, W., Davis, S. \& Hansen, H. (2008). In situ simulation: A method of experiential learning to promote safety and team behavior. Journal of Perinatal \& Neonatal Nursing, 22 (2), 105-113.

Morey, J., Simon, R., Jay, G., Wears, R., Salisbury, M., Dukes, K. \& Berns, S. (2002). Error reduction and performance improvement in the emergency department 
through formal teamwork training: Evaluation results of the med-teams Project. Health Services Research, 37(6), 1553-1581.

Patient Safety Advisory Group. (2011, December). The Joint Commission Sentinel Event Alert. A complimentary publication of The Joint Commission (Issue 48). Retrieved from The Joint Commission website: http://www.jointcommission.org

Pronovost, P., Berenholtz, S., Goeschel, C., Thom, I., Watson, S., Holzmueller, C., ...Sexton, J.B. (2008). Improving patient safety in intensive care units in Michigan. Journal of Critical Care, 23, 207-221.

Rasmussen J. (1990). The role of error in organizing behaviour. Ergonomics, 33(10/11), $1185-1199$.

Reason J.T. (1990). Human Error. Cambridge University Press.

Reason, J.T. (2000). Human error: Models and management. BMJ, 320(768), 768--770. doi: $10.1136 / \mathrm{bmj} .320 .7237 .768$

Rogers, A., Hwang, W., Scott, L., Aiken, L. \& Dinges, D. (2004). The working hours of hospital staff nurses and patient safety. Health Affairs, 23(4), 202-212.

Rothschild, J., Landrigan, C., Cronin, J., Kaushal, R., Lockley, S., Burdick, E., ...Bates, D. (2005). The critical care safety study: The incidence and nature of adverse events and serious medical errors in intensive care. Critical Care Medicine, 33(8), 1694-1700.

Scott, L., Rogers, A., Hwang, W. \& Zhang, Y. (2006). Effects of critical care nurse's work hours on vigilance and patients' safety. American Journal of Critical Care, 15(1), 30-37. 
Sexton, B., Helmreich, R., Neilands, T., Rowan, K., Vella, D., Boyden, J., ... Thomas, E. (2006, April 03). The Safety Attitudes Questionnaire: Psychometric properties, benchmarking data, and emerging research [Online exclusive]. BMC Health Services Research. doi: 10.1186/1472-6963-6-44

Sexton, J.B., Thomas, E., \& Helmreich, R., (2000). Error, stress and teamwork in medicine and aviation: Cross sectional surveys. $B M J, 320(18), 745-749$. Retrieved from http://www.bmj.com

Shapiro, M. J., Morey, J.C., Small, S.D., Langford, V., Kaylor, C.J., Jagminas, L., ...Jay, G.D., (2004). Simulation based teamwork training for emergency department staff: does it improve clinical team performance when added to an existing didactic teamwork curriculum? Quality Safety in Health Care, 13(6), 417-21.

Sharpe, R., Koval, V., Ronco, J., Dodek, P., Wong, H., Shepard, J., ...Ayas, N. (2010). The impact of prolonged continuous wakefulness on resident clinical performance in the intensive care unit: A patient simulator study. Critical Care Medicine, 38(3), 766-770.

The Joint Commission. (2010). the Joint Commission's Electronic Accreditation Manual 2010. Retrieved from The Joint Commission Website: http://www.jointcommission.org/standards_information/edition.aspx

The Joint Commission. (2011, October). Sentinel event data root causes by event type 2004-third quarter 2011 (statistics data report). Retrieved from The Joint Commission website: http://www.jointcommission.org/sentinel_event.aspx 
West, C., Tan, A., Habermann, T., Sloan, J. \& Shanafelt, T. (2009). Association of resident fatigue and distress with perceived medical errors. The Journal of the American Medical Association, 302 (12), 1294-1300.

Wetzel, C., Kneebone, R., Woloshynowych, M., Nestel, D., Moorthy, K., Kidd, J. \& Darzi, A. (2006). The effects of stress on surgical performance. The American Journal of Surgery, 191, 5-10. doi:10.1016/j.amjsurg.2005.08.034 
Table 1

Pre and Post Mean Scores on the TAQ and SAS Surveys $(N=27)$

\begin{tabular}{|c|c|c|c|c|c|c|c|}
\hline \multicolumn{4}{|c|}{ TAQ } & \multicolumn{4}{|c|}{ SAS } \\
\hline Item & Pre & Post & Change & Item & Pre & Post & Change \\
\hline Team Structure & 1.636 & 1.265 & -0.371 & Stress Recognition & 2.513 & 1.968 & -0.545 \\
\hline TS1 & 1.296 & 1.111 & -0.185 & SA1 & 1.926 & 1.259 & -0.667 \\
\hline TS2 & 1.185 & 1.037 & -0.148 & SA2 & 1.963 & 1.63 & -0.333 \\
\hline TS3 & 1.815 & 1.444 & -0.371 & SA3 & 1.63 & 1.185 & -0.445 \\
\hline TS4 & 2 & 1.519 & -0.481 & SA4 & 3.222 & 2.296 & -0.926 \\
\hline TS5 & 1.667 & 1.222 & -0.445 & SA5 & 2.593 & 1.741 & -0.852 \\
\hline TS6 & 1.852 & 1.259 & -0.593 & SA6 & 2.148 & 1.37 & -0.778 \\
\hline Leadership & 1.296 & 1.099 & -0.197 & SA7 & 2.259 & 1.407 & -0.852 \\
\hline TS7 & 1.148 & 1.074 & -0.074 & SA8 & 3.185 & 3.296 & 0.111 \\
\hline TS8 & 1.296 & 1.037 & -0.259 & SA9 & 3.852 & 3.519 & -0.333 \\
\hline TS9 & 1.333 & 1.148 & -0.185 & SA10 & 3.259 & 2.704 & -0.555 \\
\hline TS10 & 1.37 & 1.148 & -0.222 & Sa11 & 4.148 & 3.556 & -0.592 \\
\hline TS11 & 1.37 & 1.111 & -0.259 & SA12 & 1.556 & 1.074 & -0.482 \\
\hline TS12 & 1.259 & 1.074 & -0.185 & SA13 & 1.889 & 1.259 & -0.63 \\
\hline Situation Monitor & 1.525 & 1.204 & -0.320 & SA14 & 1.556 & 1.259 & -0.297 \\
\hline TS13 & 1.519 & 1.259 & -0.26 & & & & \\
\hline TS14 & 1.444 & 1.111 & -0.333 & & & & \\
\hline TS15 & 1.667 & 1.259 & -0.408 & & & & \\
\hline TS16 & 1.593 & 1.222 & -0.371 & & & & \\
\hline TS17 & 1.407 & 1.111 & -0.296 & & & & \\
\hline TS18 & 1.519 & 1.259 & -0.26 & & & & \\
\hline Mutual Support & 1.475 & 1.216 & -0.259 & & & & \\
\hline TS19 & 1.481 & 1.148 & -0.333 & & & & \\
\hline TS20 & 1.481 & 1.259 & -0.222 & & & & \\
\hline TS21 & 1.296 & 1.111 & -0.185 & & & & \\
\hline TS22 & 1.556 & 1.259 & -0.297 & & & & \\
\hline TS23 & 1.37 & 1.074 & -0.296 & & & & \\
\hline TS24 & 1.667 & 1.444 & -0.223 & & & & \\
\hline Communication & 1.747 & 1.185 & -0.562 & & & & \\
\hline TS25 & 1.704 & 1.111 & -0.593 & & & & \\
\hline TS26 & 2 & 1.148 & -0.852 & & & & \\
\hline TS27 & 1.556 & 1.148 & -0.408 & & & & \\
\hline TS28 & 1.815 & 1.148 & -0.667 & & & & \\
\hline TS29 & 1.481 & 1.111 & -0.37 & & & & \\
\hline TS30 & 1.926 & 1.444 & -0.482 & & & & \\
\hline
\end{tabular}

Note. Smaller pre post score values indicate greater agreement with concept 


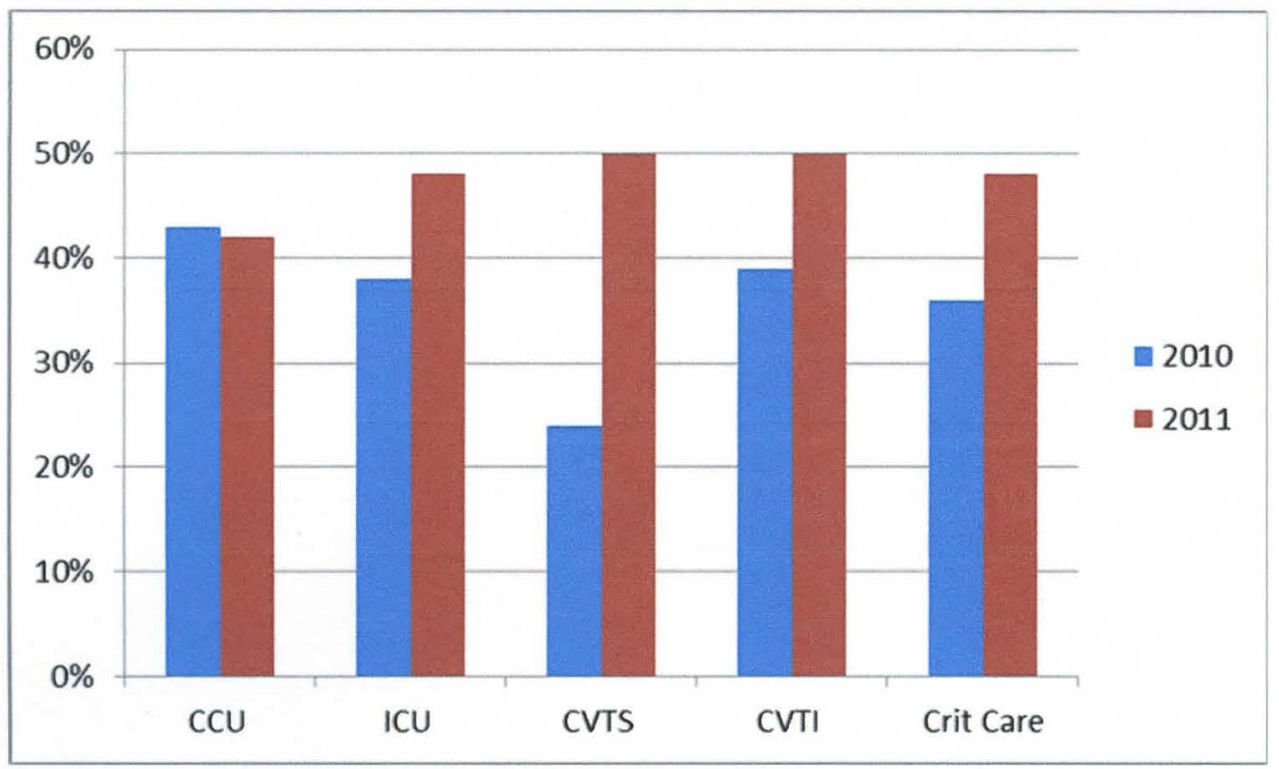

Figure 1

SAQ Stress Recognition Scale scores expressed as \% positive (those answering slightly or strongly agree) for each unit and critical care as a whole. Comparison of 2011 scores (after training) to 2010 scores (prior to training). 


\author{
Appendix A \\ Recruitment Flyer
}

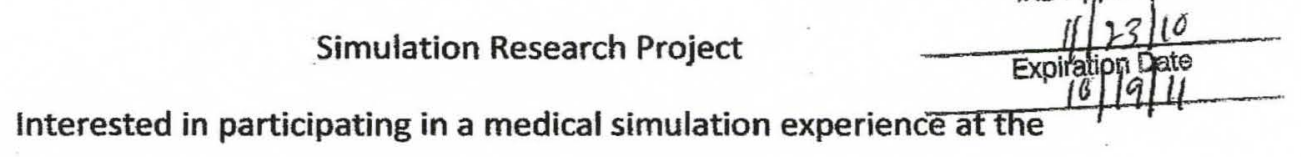

Rhode Island College SON simulation lab?
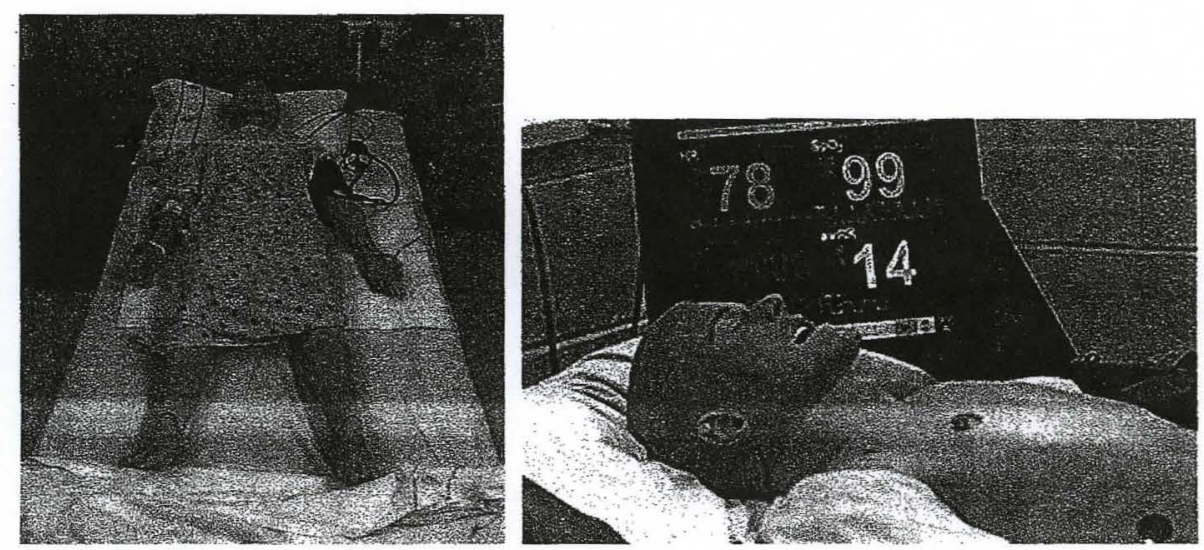

We are conducting a research study to determine the effect of a simulation educational experience on critical care staff's attitudes toward aspects of safety culture.

All Miriam Hospital critical care professionals who provide direct patient care i.e. Physicians, Nurses, Physicians Assistants, Respiratory therapists are invited to participate. Participation is completely voluntary.

Participation would involve attending a one day educational session at Rhode Island College SON simulation lab which is part classroom and part high fidelity simulation. Participation would also involve answering some surveys. Six sessions will be offered. Each session can accommodate 8 participants. Dates will be posted as soon as sessions are scheduled and will take place in January 2011.

Six Continuing Education Credits will be offered. There is no charge for the educational experience. Refreshments will also be provided during breaks.

More information will be provided prior to the session so that you may make an informed decision whether or not to participate.

Please contact Heidi Paradis by email hparadis@lifespan.org or by phone at 401793-3630 if you are interested in participating or for more information. 


\author{
Appendix B \\ Informational Letter for Simulation Educational Session
}

\begin{abstract}
The Miriam triospital tAB Approved

Research Informational Sheet

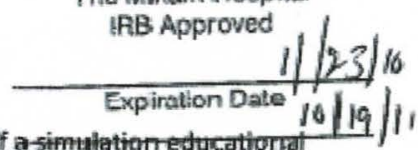

We would like to ask you to take part in a research study called " Effects of a-simulationeducatiormil experience on critical care staff's recognition of stressors affecting performance and use of teamwork skills" that will measure changes in your attitudes/opinions before and after this full day training session by your completion of three different surveys.
\end{abstract}

If you choose to participate you will be: asked to answer two surveys prior to the training. One survey contains 15 questions and the other contains 30 questions. We would like you to show that you agree or disagree with the statement by checking the box. The day of training will include a four hour classroom educational experience where you will learn about causes of medical error and teamwork skills followed by a four hour high fidelity simulation experience to practice these skills. These experiences invalve role playing with lifelike mannequins to practice care in a realistic setting. Simulations provide a safe setting where learning can take place without harming patients. Each of three simulations is followed by a debriefing where you will view a video of the simulation and discuss what you thought, felt and learned. If you would not like to be in the video you may choose not to participate in the simulation. No video is saved or stored; it is erased immediately after use during debriefing. No one will view the video except those present during the simulation. You would be asked at the end of the training day to answer the same two surveys. You would then be asked, several months after the training, to answer a third, electronic survey containing 31 questians. A link will be sent via lifespan email. Answering this survey is also voluntary. All of the surveys would ask questions about your attitudes and opinions related to medical error, patient safety and teamwork. There are no questions that are personal, sensitive or that should cause you any discomfort. The surveys should take about 15 -30 minutes to complete.

All surveys will be kept confidential and viewed only by the researcher. None of the information provided by you will have your name or any identifiable number on it. You will make up a code of your choosing to link the before and after surveys but the code cannot be linked directly to you. Resulits as a whole may be shared with others but no individual information can be linked dinectly to you.

Participation is completely voluntary. You will not be evaluated and there will be no consequence to your employment status as a result of participating or not partici pating. It is expected of all those who participate that no discussion outside of the training will take place about the performance of others during simulations. The classroom and simulation activities are for educational purposes only and should be informational and enjoya ble. There will be several short breaks and one longer break during the day. Refreshments will be prowided. You may choose to withdraw from the study at any time by notifying the researcher (Heidi Paradis) or assistants.

There may be no direct benefit to you for participating or for answering the surveys however, you may kesep all materials provided in the class. If you choose to complete the entire training. you will receive 6 contact hours of continuing education approved by the Rhode Island State Nurses Association. We are hoping that the education will enhance your practice and the information you provide will help to ensure safer patient care. 
The risks of participating in this study are minimal meaning they are about the same as you would experience in your normal work activities. You will be given an orientation to the simulation environment and mannequins so that you will know what to expect. You may ask questions at any time if you are unsure of what to do. If you decide you do not wish to continue at any time you may stop by notifying the researcher, one of the assistants or any of the simulation lab personnel.

If you have any questions about the research study or about the surveys or the educational sessions please feel free to ask the researcher and/or assistants before we begin or you can call the researcher, Heidi Paradis, at any time at 401-793-3630.

If you cannot reach the researcher or if you have any questions about your rights as a research subject, or any concerns about your participation, please feel free to call the Lifespan Office of Research Administration manager Patricia Houser at 401-444-6246 or the Chair of the Rhode Island College Institutional Review Board at IRB@ric.edu or by phone at 401-456-8228.

Thank you for your time.

Heidi Paradis RN

Rhode Island College graduate nursing student

Critical Care Educator Miriam Hospital 


\author{
Appendix C \\ Safety Attitudes Survey \\ (Subscale of University of Texas SAQ ICU version 2004)
}

The success of the survey depends on your contribution, so it is important that you answer questions as honestly as you can. There are no right or wrong answers, and often the first answer that comes to mind is best. All data are strictly confidential. No individual feedback will be given to your supervisors or colleagues, so feel free to express your opinion. Your participation in the study is valued and appreciated. Please place a checkmark in the box that matches your level of agreement with the statement.

\begin{tabular}{|c|c|c|c|c|c|}
\hline Statement & $\begin{array}{l}\text { Disagree } \\
\text { Strongly }\end{array}$ & $\begin{array}{l}\text { Disagree } \\
\text { Slightly }\end{array}$ & Neutral & $\begin{array}{c}\text { Agree } \\
\text { Slightly }\end{array}$ & $\begin{array}{c}\text { Agree } \\
\text { Strongly }\end{array}$ \\
\hline \multicolumn{6}{|l|}{$\begin{array}{l}\text { We should be aware of and sensitive to the } \\
\text { personal problems of other ICU team } \\
\text { members. }\end{array}$} \\
\hline \multicolumn{6}{|l|}{ I am less effective when stressed or fatigued } \\
\hline \multicolumn{6}{|l|}{$\begin{array}{l}\text { Team members should monitor each other for } \\
\text { signs of stress or fatigue. }\end{array}$} \\
\hline \multicolumn{6}{|l|}{$\begin{array}{l}\text { Team members should feel obligated to } \\
\text { mention their own psychological stress or } \\
\text { physical problems to other ICU personnel. }\end{array}$} \\
\hline \multicolumn{6}{|l|}{$\begin{array}{l}\text { Personal problems can adversely affect my } \\
\text { performance. }\end{array}$} \\
\hline \multicolumn{6}{|l|}{$\begin{array}{l}\text { Effective ICU team coordination requires } \\
\text { members to take into account the personalities } \\
\text { of other team members. }\end{array}$} \\
\hline \multicolumn{6}{|l|}{$\begin{array}{l}\text { When my workload becomes excessive, my } \\
\text { ability to concentrate is impaired. }\end{array}$} \\
\hline \multicolumn{6}{|l|}{$\begin{array}{l}\text { Even when fatigued, I perform effectively } \\
\text { during critical phases of patient care. }\end{array}$} \\
\hline \multicolumn{6}{|l|}{$\begin{array}{l}\text { My decision-making ability is as good in } \\
\text { medical emergencies as in routine situations. }\end{array}$} \\
\hline \multicolumn{6}{|l|}{$\begin{array}{l}\text { My performance is not affected by working } \\
\text { with an inexperienced or less capable team } \\
\text { member. }\end{array}$} \\
\hline \multicolumn{6}{|l|}{$\begin{array}{l}\text { A truly professional team member can leave } \\
\text { personal problems behind when working in } \\
\text { the ICU. }\end{array}$} \\
\hline \multicolumn{6}{|l|}{$\begin{array}{l}\text { There are strategies that can be employed to } \\
\text { help prevent errors. }\end{array}$} \\
\hline \multicolumn{6}{|l|}{$\begin{array}{l}\text { I am not aware of any strategies that help } \\
\text { prevent errors. }\end{array}$} \\
\hline $\begin{array}{l}\text { I frequently use strategies to help prevent } \\
\text { errors. }\end{array}$ & & & & & \\
\hline
\end{tabular}

Note: The SAQ is available online at:

http://www.uth.tmc.edu/schools/med/imed/patient_safety/questionnaires/SAQBibliography.html Citation for the full survey is: Sexton JB, Helmreich RL, Neilands TB, Rowan K, Vella K, Boyden J, Roberts PR, Thomas EJ. The Safety Attitudes Questionnaire: Psychometric Properties, Benchmarking Data, and Emerging Research. BMC Health Services Research 2006; 6:44 
Appendix D

TAQ Survey

\section{TeamSTEPPS}

\section{TeamSTEPPS $^{\mathrm{TM}}$ Teamwork Attitudes Questionnaire}

The purpose of this survey is to measure your impressions of various components of teamwork as it relates to patient care and safety.

Instructions: Please respond to the questions below by placing a check mark $(v)$ in the box that corresponds to your level of agreement from Strongly Disagree to Strongly Agree. Please select only one response for each question.

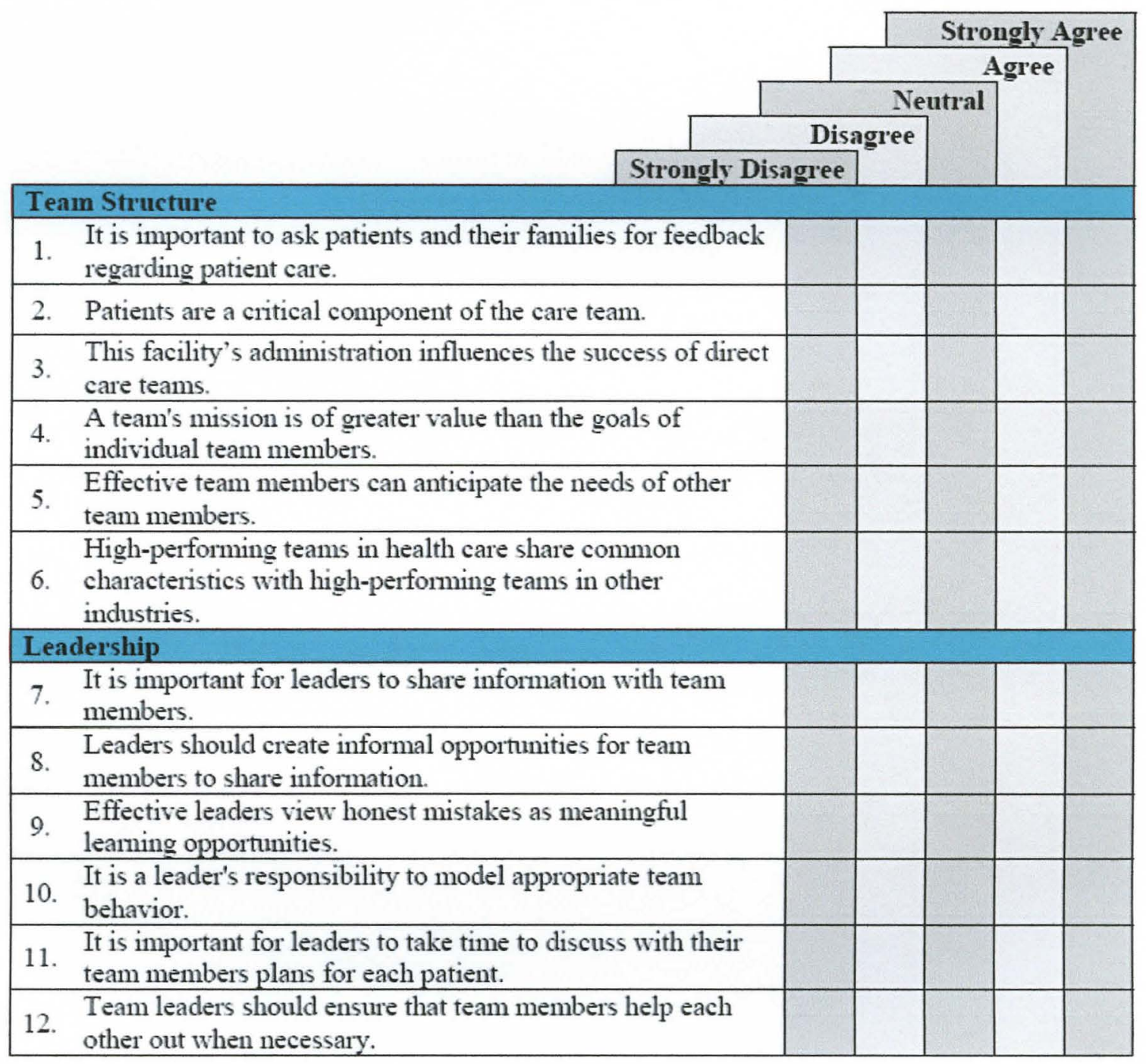




\section{TeamSTEPPS}

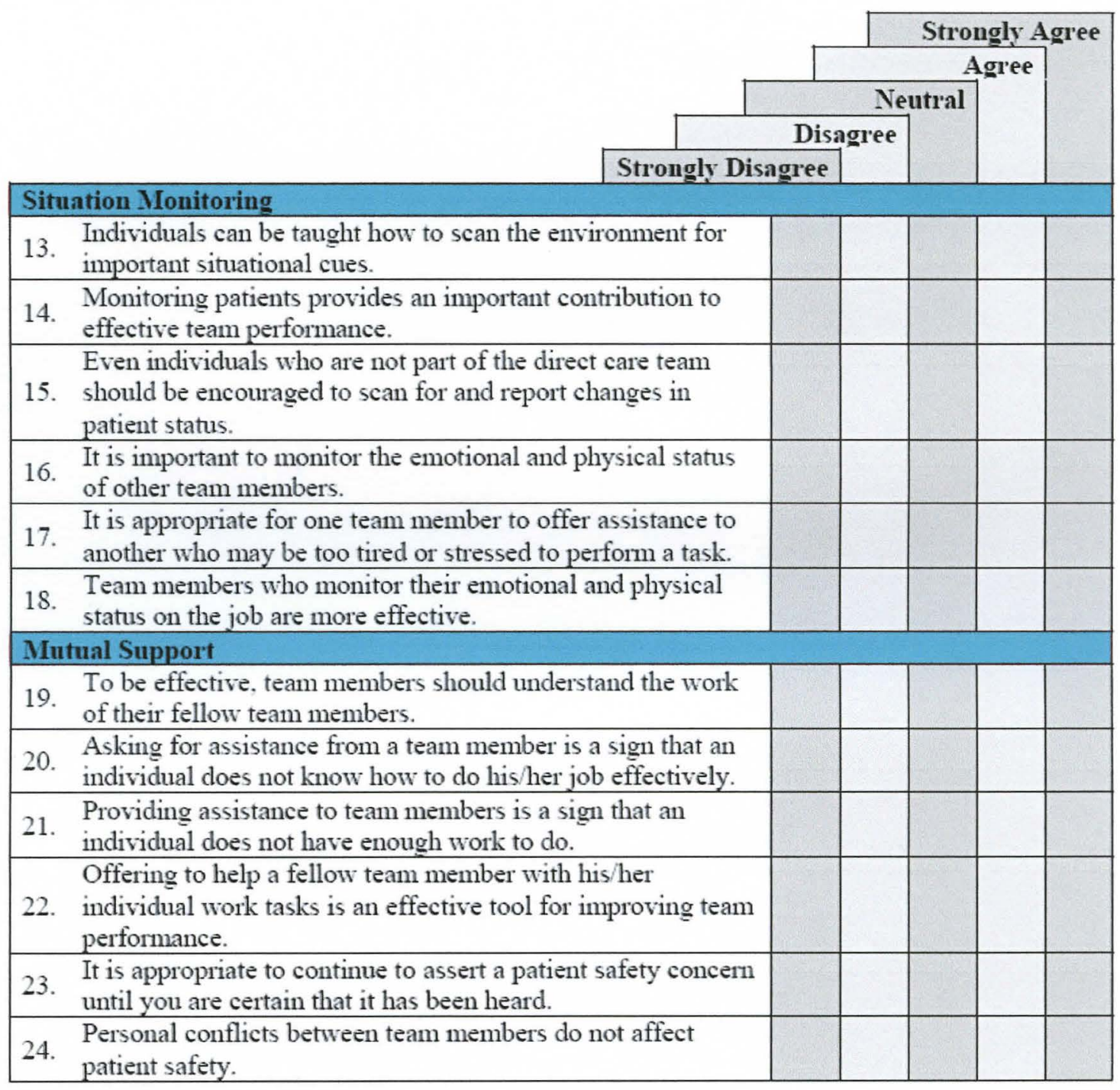

PLEASE CONTINUE TO THE NEXT PAGE 
Appendix E

SAQ Survey

\section{Safety Attitude Questionnaire Items}

\section{Teamwork Climate}

It is easy for personnel in this ICU to ask questions when there is something that they do not understand.

I have the support I need from other personnel to care for patients.

Nurse input is well received in this ICU.

In this ICU, it is difficult to speak up if I perceive a problem with patient care.

Disagreements in this ICU are resolved appropriately (i.e., not who is right, but what is best for the patient)

The physicians and nurses here work together as a well-coordinated team.

\section{Safety Climate}

The culture in this ICU makes it easy to learn from the errors of others.

Medical errors are handled appropriately in this ICU.

I know the proper channels to direct questions regarding patient safety in this ICU.

I am encouraged by my colleagues to report any patient safety concerns I may have

I receive appropriate feedback about my performance.

I would feel safe being treated here as a patient.

In this ICU, it is difficult to discuss errors.

\section{Job Satisfaction}

This hospital is a good place to work.

I am proud to work at this hospital.

Working in this hospital is like being part of a large family.

Moral in this ICU area is high.

I like my job.

\section{Stress Recognition}

When my workload becomes excessive, my performance is impaired.

I am more likely to make errors in tense or hostile situations.

Fatigue impairs my performance during emergency situations (e.g., emergency

resuscitation, seizure).

I am less effective at work when fatigued.

\section{Perceptions of Management}

Hospital management does not knowingly compromise the safety of patients.

Hospital administration supports my daily efforts.

I am provided with adequate, timely information about events in the hospital that might affect my work.

The levels of staffing in this clinical area are sufficient to handle the number of patients 


\section{Working Conditions}

All the necessary information for diagnostic and therapeutic decisions is routinely available to me.

This hospital constructively deals with problem physicians and employees.

Trainees in my discipline are adequately supervised.

This hospital does a good job of training new personnel.

Note: The SAQ is available online at:

http://www.uth.tmc.edu/schools/med/imed/patient_safety/questionnaires/SAQBibliography.html Citation for the full survey is: Sexton JB, Helmreich RL, Neilands TB, Rowan K, Vella K, Boyden J, Roberts PR, Thomas EJ. The Safety Attitudes Questionnaire: Psychometric Properties, Benchmarking Data, and Emerging Research. BMC Health Services Research 2006; 6:44. Participants indicated their level of agreement with these statements by choosing 1=Disagree Strongly, 2=Disagree Slightly, 3=Neutral, 4=Agree Slightly, 5=Agree Strongly. This survey was administered in electronic format and also asked participants what type of unit they work on and how many years of experience they had. Results were viewed in aggregate per clinical unit; no data was linked to individuals. 
Appendix F

Course Agenda

TeamSTEPPS ${ }^{\circledR}$ Fundamentals Course Agenda

\begin{tabular}{|c|c|c|}
\hline Time & Topic & Time allotted \\
\hline 8:00 am-8:40am & $\begin{array}{l}\text { Welcome/Informed Consent } \\
\text { Surveys }\end{array}$ & 40 Minutes \\
\hline $8: 40-9: 10$ & $\begin{array}{l}\text { Introduction: } \\
\text { Error } \\
\text { Factors affecting Performance } \\
\text { Teamwork as a strategy }\end{array}$ & 30 Minutes \\
\hline $9: 10-9: 40$ & Team Structure & 30 minutes \\
\hline $9: 40-9: 50$ & Break & 10 minutes \\
\hline $9: 50-10: 20$ & Leadership & 30 minutes \\
\hline $10: 20-10: 50$ & Situation Monitoring & 30 minutes \\
\hline $10: 50-11: 20$ & Mutual Support & 30 minutes \\
\hline $11: 20-11: 30$ & Break & 10 minutes \\
\hline $11: 30-12: 00$ & Communication & 30 minutes \\
\hline $12: 00-12: 20 \mathrm{pm}$ & Putting it All Together & 20 minutes \\
\hline 12:20-1:00pm & Lunch & 40 minutes \\
\hline $1: 00-1: 25 \mathrm{pm}$ & $\begin{array}{l}\text { Orientation to Simulation } \\
\text { Environment }\end{array}$ & 25 minutes \\
\hline $1: 25-2: 10 \mathrm{pm}$ & $\begin{array}{l}\text { Simulation } 1 \\
\text { Debriefing }\end{array}$ & $\begin{array}{l}15 \text { minutes } \\
30 \text { minutes }\end{array}$ \\
\hline $2: 10-2: 20 \mathrm{pm}$ & Break & 10 minutes \\
\hline $2: 20-3: 05 \mathrm{pm}$ & $\begin{array}{l}\text { Simulation } 2 \\
\text { Debriefing }\end{array}$ & $\begin{array}{l}15 \text { minutes } \\
30 \text { minutes }\end{array}$ \\
\hline 3:05-3:15pm & Break & 10 minutes \\
\hline $3: 15-4: 00 \mathrm{pm}$ & $\begin{array}{l}\text { Wrap Up: } \\
\text { Take Aways } \\
\text { Post surveys } \\
\text { Evaluations } \\
\text { CEU Presentation } \\
\end{array}$ & 45 minutes \\
\hline
\end{tabular}




\author{
Appendix G \\ Program Evaluations Summary \\ RISNA Continuing Education \\ Program Evaluation Summary \\ TeamSTEPPS ${ }^{\circledR}$
}

Each participant must complete an evaluation to receive a Contact hour certificate for this educational activity. Please be as honest and objective as possible.

1. Rate the extent to which the objectives were met by circling the appropriate number.

\begin{tabular}{|l|c|c|c|}
\hline $\begin{array}{l}\text { Learner's achievement of each objective } \\
\text { (list each objective below) }\end{array}$ & Met 1 & Partially met 2 & Not met 3 \\
\hline Describe the TeamSTEPPS ® program & 23 & 0 & 0 \\
\hline $\begin{array}{l}\text { Describe the impact of errors and why they } \\
\text { occur. }\end{array}$ & 23 & 0 & 0 \\
\hline $\begin{array}{l}\text { Identify characteristics of high performing } \\
\text { teams. }\end{array}$ & 23 & 0 & 0 \\
\hline Describe benefits of teamwork. & 23 & 0 & 0 \\
\hline Describe the role of a team leader. & 23 & 0 & 0 \\
\hline $\begin{array}{l}\text { Describe strategies used by effective team } \\
\text { leaders. }\end{array}$ & 23 & 0 & 0 \\
\hline $\begin{array}{l}\text { Define situational awareness and how it can } \\
\text { prevent error. }\end{array}$ & 23 & 0 & 0 \\
\hline $\begin{array}{l}\text { Define how the STEP process helps to } \\
\text { monitor the environment. }\end{array}$ & 23 & 0 & 0 \\
\hline $\begin{array}{l}\text { Define Mutual Support \& Discuss barrier } \\
\text { tools, strategies, and outcomes of mutual } \\
\text { support. }\end{array}$ & 23 & 0 & 0 \\
\hline $\begin{array}{l}\text { Recognize connection between } \\
\text { communication and medical error. }\end{array}$ & 23 & 0 & 0 \\
\hline $\begin{array}{l}\text { Identify and discuss barriers, tools, strategies } \\
\text { and outcomes to communication. }\end{array}$ & 23 & 0 & 0 \\
\hline $\begin{array}{l}\text { Discuss how to apply the tools and strategies } \\
\text { presented and how to overcome barriers. }\end{array}$ & 23 & 0 & 0 \\
\hline $\begin{array}{l}\text { Demonstrate use of tools and strategies } \\
\text { presented above during simulated scenarios. }\end{array}$ & 23 & 0 & 0 \\
\hline $\begin{array}{l}\text { States take-aways from experience \& Discuss } \\
\text { how learning can be applied to future practice. }\end{array}$ & 23 & 0 & 0 \\
\hline
\end{tabular}


2. Rate the relevance of the objectives to overall purpose/goals.

\begin{tabular}{|l|c|c|c|}
\hline & 1 Related & 2 Partially & 3 Not related \\
\hline $\begin{array}{l}\text { Relevance of the objectives to overall } \\
\text { purpose/goals of the educational activity. }\end{array}$ & 23 & 0 & 0 \\
\hline
\end{tabular}

3. Rate the teaching expertise of the presenter.

\begin{tabular}{|l|c|c|c|}
\hline Evaluation of presenter: Heidi Paradis & Met 1 & Partially met 2 & Not met 3 \\
\hline Speaker's expertise enhanced the activity. & 23 & 0 & 0 \\
\hline $\begin{array}{l}\text { Teaching strategies were appropriate for } \\
\text { the objectives and content. }\end{array}$ & 23 & 0 & 0 \\
\hline $\begin{array}{l}\text { Evaluation of presenter: Lois Ginsberg } \\
\text { taught one less class) }\end{array}$ & Met & Partially met & Not met \\
\hline Speaker's expertise enhanced the activity. & 20 & 0 & 0 \\
\hline $\begin{array}{l}\text { Teaching strategies were appropriate for } \\
\text { the objectives and content. }\end{array}$ & 20 & 0 & 0 \\
\hline
\end{tabular}

4. Rate the appropriateness of physical facilities.

\begin{tabular}{|l|c|c|c|}
\hline & Appropriate & $\begin{array}{c}\text { Somewhat } \\
\text { appropriate }\end{array}$ & $\begin{array}{c}\text { Not } \\
\text { appropriate } \\
\end{array}$ \\
& 1 & 2 & 3 \\
\hline Appropriateness of physical facilities & 22 & 1 & 0 \\
\hline
\end{tabular}

5. Conflict of interest disclosure

\begin{tabular}{|c|c|c|c|}
\hline & Met 1 & Not met 2 & N/A 3 \\
\hline Conflict of Interest disclosed & 23 & 0 & 0 \\
\hline
\end{tabular}

\section{Participant Comments:}

Great Job as always!

Heidi made class fun and informative and gave something to take back to clinical environment.

Very helpful. Should be mandatory for all personnel involved in patient care to take course to improve care and patient safety.

Important that included actual leaders to be one of presenters and share barriers.

Manikins very helpful. Being able to listen to lung sounds and feel pulse made situation more realistic and fun.

Suggest: More time with manikins to be able to function in more familiar environment. Allow participants to "play" with manikins, lead placement and how to use monitors before actual simulation.

\section{Recommendations for future programs:}

Make program mandatory for all hospital employees, helps focus on importance of team work which is a daily requirement for a facility to run effectively.

Talk about conflict during a situation when something has to be addressed right then and how to do it.

Include more simulated scenarios for more practice. More heat in room. 